\title{
DIGITAL HYBRID LEARNING INDIVIDUAL QUALITY ASSESSMENT IN EUROPEAN AND ORIENTAL LANGUAGES PROGRAMS: STUDENT CASE STUDY IN UKRAINE
}

\author{
Rusudan Makhachashvili and Ivan Semenist \\ Borys Grinchenko Kyiv University \\ Bulvarno-Kudryavska-st., 18/2, Kyiv, Ukraine
}

\begin{abstract}
The global pandemic and subsequent quarantine measures and restrictions have posed an array of challenges to the structure and procedure of higher education workflow, which significantly influenced the scope of individual experiences, projected outcomes and estimated quality of higher education in countries across the world. This study focus is the in-depth assessment of the case of individual digital distance and blended learning experiences by students of different tiers (Bachelor's level, Master's level, Graduate school level) in European (French, Italian, Spanish, English) and Oriental (Mandarin Chinese, Japanese) Languages university level programs at Borys Grinchenko Kyiv University of Ukraine through the span of educational activities in the time-frame of COVID-19 quarantine measures of March 2020 to January 2021. The survey and analysis of different ICT tools is used to assess the parameters and challenges of individual quality and efficiency of translation of the real life Foreign Languages Acquisition practices into digital hybrid format, involving activation of interdisciplinary skills and cross-sectorial activities, assisted by ICT tools. The online survey of over 300 students of European and Oriental Languages programs provides for disclosure of a comprehensive case of student satisfaction with digitized foreign languages education, systematized individual experiences and quality estimation of e-learning and hybrid learning in the framework of COVID-19 lockdown; assessment of individual experiences and quality of e-learning and hybrid learning in the framework of COVID-19 lockdown as compared to traditional, face-to-face learning formats for foreign languages; individual quality assessment of learning process design, programmed learning outcomes and projected competencies for university programs of Oriental and European languages in the framework of COVID-19 lockdown and quarantine measures.
\end{abstract}

\section{KEYWORDS}

Hybrid Learning, e-Learning, Digital Literacy, Quality Assessment, Oriental Languages, European Languages, Survey Study

\section{INTRODUCTION}

In the educational domain, according to our estimations, the result of fundamental Technospheric shift, induced by the COVID-19 pandemic development and enhanced by subsequent digitalization measures, was the need to take quick comprehensive action (Makhachashvili, Semenist et al 2020) in order to achieve such desirable results: a) to adapt the existent educational scenarios to digital, remote and blended formats; b) to activate complex interdisciplinary skill-sets, otherwise latent or underutilized in the educational process; c) to boost ICT competence and digital literacy of all participants of the educational process relocated to computer being.

The global pandemic and subsequent quarantine measures and restrictions have posed an array of challenges to the structure and procedure of higher education workflow, which significantly influenced the scope of individual experiences, projected outcomes and estimated quality of higher education in countries across the world.

Foreign Languages Acquisition at university level major programs is a rigorous process (Law OHE 2019) that involves different stages and a regimen of activities and competencies across interconnected interdisciplinary domains. The presented study is a parcel of comprehensive institutional inquiry into the toll 
digitalization and amplified use of ICT tools put on different aspects of Oriental (Mandarin Chinese and Japanese) as well as European (French, Italian, Spanish, English) languages acquisition efficiency, assessment management, programmed results, communicative and digital competency formation in COVID-19 lockdown paradigm.

The research project to date spans the following areas: 1) full survey datasets on in-depth subjective experiences of students in e-learning and blended learning in COVID-19 timeframe for stakeholders of Oriental languages (Mandarin Chinese and Japanese) and European Languages (French, Italian, Spanish, English) major programs in capital city and regional universities of Ukraine; 2) full survey datasets on in-depth subjective experiences of faculty and staff in e-learning and blended learning in COVID-19 timeframe for stakeholders of Oriental languages (Mandarin Chinese and Japanese) and European Languages (French, Italian, Spanish, English) major programs in capital city and regional universities of Ukraine.

The accumulated data so far has been seminal for a range of publications (Makhachashvili, Semenist et al 2020; Makhachashvili, Semenist, Bakhtina 2020), covering the issues of ICT tools efficiency rating regimen for foreign languages programs, isolated and comparative case studies of Oriental and European languages acquisition digitization procedures and best practices.

The estimations of digital distant education quality, conducted across various studies in the pre-COVID-19 inquiry framework have spanned, among others, assessment of satisfaction with distance learning experience (Bekele 2010; Bolliger 2009); added value of online learning (Thiessen, Ambrock 2011); evaluation of learning outcomes (Costareie 2011; Ni 2013); overall attitudes to distance learning (Salyers et al 2014); challenges of online education (Markova et al 2017), networking principles in e-learning (Smyrnova-Trybulska, Kommers et al 2019).

These issues require a comprehensive revisit in terms of the toll the global pandemic took on individual learning experiences and subsequent shift in quality estimations of linguistic education in universities due to the abrupt transition to exclusively distant, digital distant or hybrid learning formats as a mode of formal education and university degree acquisition (as opposed to being a mostly auxiliary learning method or an informal learning format).

This study objective, henceforth, is to critically review the satisfaction parameters of via in-depth assessment of individual digital distance and hybrid learning experiences and best practices by students of Oriental (Mandarin Chinese, Japanese) and European (French, Italian, Spanish, English) Languages university level programs in Borys Grinchenko Kyiv University (BGKU) through the span of educational activities in the time-frame of COVID-19 quarantine measures of March 2020 to January 2021. The survey and analysis of different ICT tools is used to assess the parameters and challenges of individual quality and efficiency of translation of the real life Foreign Languages Acquisition practices into digital blended format, that Borys Grinchenko Kyiv University adopted comprehensively across the board, involving activation of interdisciplinary skills and cross-sectorial activities, assisted by ICT tools.

The study premise is based on identification of various digital distant learning formats (u-learning, m-learning, hybrid learning) (Crowe 2007) and modes for university educational programs and projected digital literacy requirements (EC 2020; DGR 2019; WEF 2020). Within the parameters of this study we estimate digitally enhanced or electronic learning (e-learning) as a form of ubiquitous learning (u-learning) that involves learning in an environment with full access to digital devices and services at any given moment (Van't Hooft 2007).

The framework evolution and innovation of e-learning as a complex system of human activity in the digital age, is determined by a range of qualifying conditions of its emergence, existence and transformation in the COVID-19 timeframe, including: 1) exhaustive synchronization of the object, phenomenological and anthropological planes of educational activities and proceedings processes ICT development; 2) exhaustive output of parameterization isomorphism of ontological (substance phenomenological), anthropic and digitized structures of reality and educational activity; 3 ) flexibility, adaptability and dynamic potential of the educational activities enhanced by ICT tools and digital technology (that is fulfilled, in particular through info-capacity, sign hybridization, the evolution of the basic ontological and functional features of the learning process).

COVID-19 quarantine measures, put in place country-wide in educational institutions Ukraine in the time spans of March-June 2020, October-December 2020 and January 2021 have demanded the simultaneous employment and overlap of the following structurally complex learning formats: e-learning 1.0 (direct synchronous computer assisted distant instruction); e-learning 2.0 (mostly asynchronous computer-supported collaborative learning, also known as "networked collaborative learning") (Trentin 2010); blended learning 
(in-person teaching with asynchronous ICT assisted learning methods) (Voorn, Kommers 2013; Dos Reis 2015; Boyarsky 2020); hybrid learning (synchronous instruction of in-presence and remote students via ICT tools) (Duff 2020).

Modelling of the comprehensive framework of educational activities and experiences in foreign language acquisition transformation into digitally enhanced format (Makhachahshvili, Semenist 2021) is, therefore, possible through an interoperable set of parameters (Figure 1): Time; Space; Communicative distance; Dependence on ICT tools and infrastructure; Level of complexity:

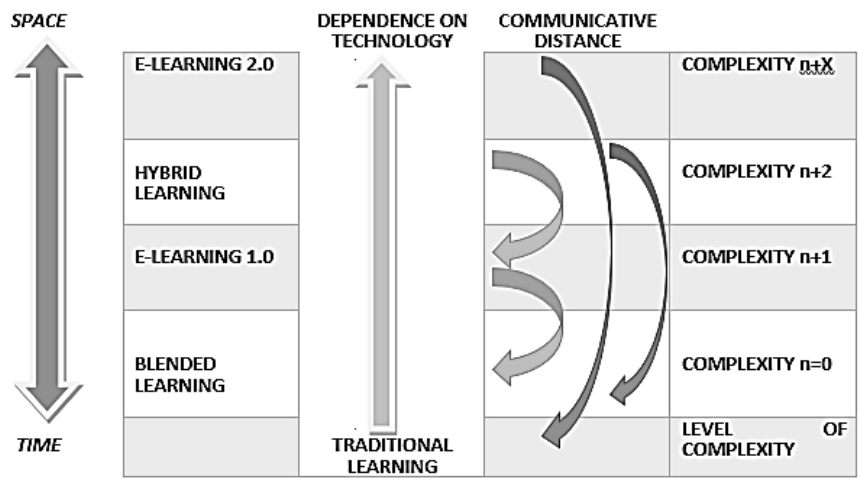

Figure 1. Modelling of Complex Digitally Enhanced Learning Formats

Based on the level of quarantine alert, adopted in the capital city of Kyiv at different intervals, different level of complexity was utilized for educational activities at Borys Grinchenko Kyiv University: e-learning 1.0/2.0 (for red and orange zones of quarantine) and hybrid learning (for yellow zones) formats were implemented.

\section{DIGITAL DISTANT AND HYBRID LEARNING STUDENT INDIVIDUAL QUALITY ASSESSMENT: SURVEY RESULTS}

\subsection{Method Overview}

The study employs the combination of mixed methods (Almalki 2016) - a proportional arrangement of quantitative and qualitative inquiry to assess in-depth aspects of subjective and individual quality estimation of digital distant and hybrid learning. The comprehensive study design methodology included the following consecutive steps: 1) distant digital learning activity, experience and application profiling; 2) The online survey method - based on D. Dillman's concept of mixed media and mixed mode surveys (Dillman 2014) applied to conduct in-depth assessment of individual digital distance and blended learning experiences and practices by relevant groups of stakeholders in Oriental and European Languages university level programs at Borys Grinchenko Kyiv University, Kyiv, Ukraine; 3) digital content analysis of individual associations with different modes of learning by relevant groups of stakeholders in Oriental and European Languages university level programs in regions of Ukraine (via corpus and text-mining tools); 4) digital distance and blended learning models and procedures adaptation and customization, tailored to the individual and group needs of stakeholders in Foreign Language Acquisition on university level.

Based on the activity profile (digital distance and blended learning in Foreign Language Acquisition) an online survey was devised to assess in-depth subjective experiences of e-learning and hybrid learning in COVID-19 timeframe (March 2020 - January 2021) for students of Oriental languages (Mandarin Chinese and Japanese) and European Languages (French, Italian, Spanish, English) major programs.

The online questionnaire comprised of 21 questions total (multiple choice, ranking/scoring and open-end/short answer types), divided into such categories: 1) questions on overall assessment of individual experiences and quality estimation of e-learning and hybrid learning in the framework of COVID-19 
lockdown and quarantine measures (March 2020 - January 2021) for university programs of Oriental (Mandarin Chinese, Japanese) and European (English, French, Spanish, Italian) and languages; 2) questions on assessment of individual experiences and quality of e-learning and hybrid learning in the framework of COVID-19 lockdown as compared to traditional, face-to-face learning formats; 3) questions on individual quality assessment of learning process design, programmed learning outcomes and projected competencies for university programs of European (English, French, Spanish, Italian) and Oriental (Mandarin Chinese, Japanese) languages in the framework of COVID-19 lockdown and quarantine measures (March 2020 January 2021).

\subsection{Data Gathering}

A sizable sample of 337 respondents total across Oriental (Mandarin Chinese, Japanese) and European (English, French, Spanish, Italian) languages at Borys Grinchenko Kyiv University took part in the survey. The following groups of stakeholders of the digital distant education in the timespan of COVID-19 pandemic measures were respondents of the survey overall languages on all three tier of educational levels according to the legislature of Ukraine (Law OHE 2019): undergraduate, graduate and post-graduate: 1) students of Bachelor's programs for Oriental (Mandarin Chinese, Japanese) and European (French, Italian, Spanish, English) languages (1st, 2nd, 3rd and 4th years of study) - 92.5\%; 2) students of Master's programs for Oriental (Mandarin Chinese, Japanese) and European (English, French, Spanish, Italian) languages (1st and 2nd years of study) $-5.7 \%$; students of Post-graduate programs for Oriental (Mandarin Chinese, Japanese) and European (French, Italian, Spanish, English) languages (1st, 2nd, 3rd and 4th years of study) - 1.8\%.

For the purposes of this paper the survey results were scaled to accommodate the sample of students of Oriental (Mandarin Chinese, Japanese) and European (French, Italian, Spanish, English) languages programs of Borys Grinchenko Kyiv University of Ukraine (Kyiv being the capital city). This limitation was adopted to assess the case of best practices of educational digitization to estimate the parameters and challenges of the individual experiences and quality assessment of e-learning and hybrid learning in the framework of COVID-19 lockdown, comprehensively implemented at Borys Grinchenko Kyiv university since the first days of the global lockdown in March of 2020 and thereon, as a parcel of the university overall digital campus implementation policy.

The overarching research project hypothesis is the observable variation in the individual perception of e-learning and hybrid learning quality of foreign languages acquisition programs by different groups of stakeholders in different regions of Ukraine and in the capital city due to an arrangement of educational (core competencies, soft skills proficiency), social and psychological (information fatigue, stress, community influence) and technological factors (digital literacy, digital divide, digital gap, pre-existing level of educational process digitization and e-learning experiences).

\subsection{Survey Results and Discussion}

Group 1 of survey questions - overall assessment of individual experiences and quality estimation of e-learning and hybrid learning in the framework of COVID-19 lockdown and quarantine measures (March 2020 - January 2021) for university programs of European (English, French, Spanish, Italian) and Oriental (Mandarin Chinese, Japanese) languages - yielded the following representative results across the board.

The assessment of overall comprehensive individual experience (or a take-away) of e-learning and hybrid learning in the framework of COVID-19 lockdown by different groups of stakeholders was conducted according to the 5-Point Likert Scale (a response scale in which responders specify their level of engagement with a statement or a parameter in five points: (1) Strongly disagree; (2) Disagree; (3) Neither agree nor disagree; (4) Agree; (5) Strongly agree (Handbook 2010). The extremum points for evaluation were 1 (maximum negative overall experience of e-learning and hybrid learning) and 5 (maximum positive overall experience of e-learning and hybrid learning).

Students of European and Oriental languages programs of all levels at Borys Grinchenko Kyiv University evaluated their comprehensive individual experience of e-learning as predominantly 4 - mostly agreeable (35.3\% of respondents), 3 - Average (30.9\%), 5 - most agreeable - 20.8\%. The average estimation of the overall individual satisfaction with e-learning and hybrid learning experience on Oriental and European Languages programs by students of Borys Grinchenko Kyiv University is $4>3$ - mostly agreeable to average. 
Qualitative assessment of the e-learning and hybrid learning was conducted through the retrospective evaluation of respondents' individual experience through the span of March 2020 to January 2021, in order identify and select the preferred features and elements of e-learning and hybrid learning among the following (Figure 2): Ability to work from home; Ability to customize of the study space (video conferencing or LMS); Adaptability and flexibility of the work schedule; Time saving for commute; Parallel performance of several tasks and activities; Opportunity to technologically diversify educational activity, educational materials and methods; Ability to adapt the structure and content of curricula of disciplines to the conditions of online learning; Ability to activate and improve different types of soft skills; Opportunity to improve digital literacy; Ability to work independently in the learning process; No need for constant interpersonal communication; Ability to engage international professionals through digital means.

Quantitative assessment demonstrated that students of European and Oriental languages programs of all levels in the surveyed university have distributed preferred features and elements of e-learning and hybrid learning and identified the significantly top ranking ones as follows (Figure 2): Saving time for commute $83.70 \%$ of respondents; Ability to work from home $-75.10 \%$; Parallel performance of several tasks and activities $-60.20 \%$; Adaptability and flexibility of the work schedule - 50.40\%; Ability to work independently in the learning process $-48.10 \%$.

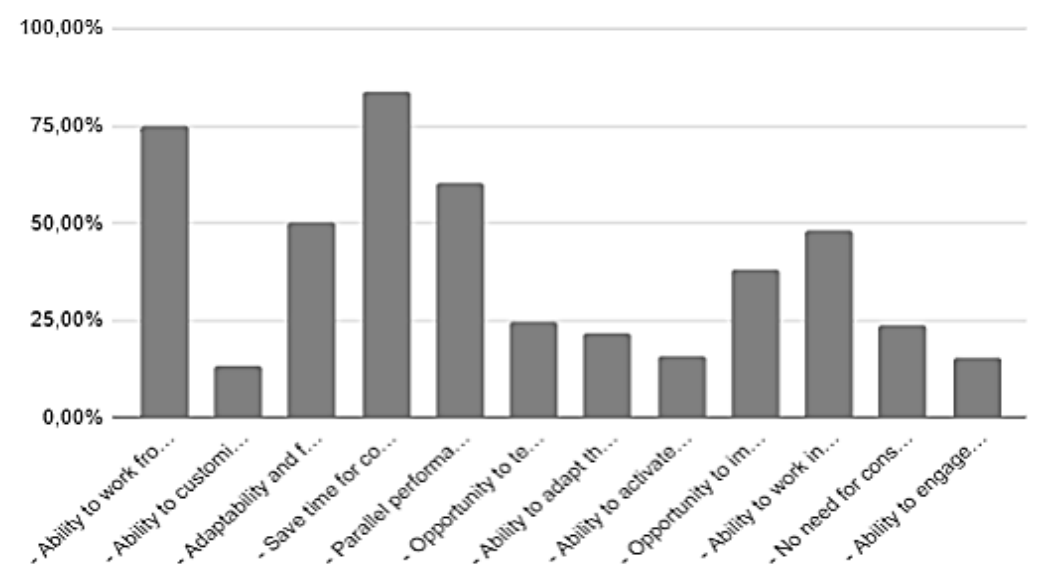

Figure 2. Top ranking of preferred features and elements of e-learning and hybrid learning: students of Oriental and European Languages programs (BGKU)

It is notable that most common preferred features of e-learning and hybrid learning by all groups of students of Oriental and European languages programs of all levels in the capital city university of Ukraine are two-fold: 1) time management due to the necessity to commute across a megapolis; 2) framework soft skills (WEF 2020), identified as relevant for the job market of the 2021-2020 timespan - flexibility, adaptability, active learning, multi-tasking.

Evaluation of respondents' individual experience through the span of March 2020 to January 2021 allowed to identify and select the features and elements of e-learning and hybrid learning, considered drawbacks, challenges or a hindrance among the following (Figure 3): Forced need to work at home (uncomfortable living conditions); Impossibility / difficulty of adaptation and flexibility of the work schedule; The need for specialized technical means of training and online communication / technical limitations; Lack of interpersonal communication with students and colleagues on a regular basis; Emotional burnout; The need to activate and improve different types of soft skills; The need to improve digital literacy; Increasing the amount of workload in preparation for training sessions and ensuring the learning process; The need to adapt the structure and content of curricula of disciplines in terms of online learning; The need to organize and control the independent work of students; Availability of mechanisms for control and accounting of the educational process

Students of Oriental and European languages programs of all levels at Borys Grinchenko Kyiv University of Ukraine have distributed drawback features and elements of e-learning and hybrid learning and identified the top ranking ones as follows (Figure 3): 


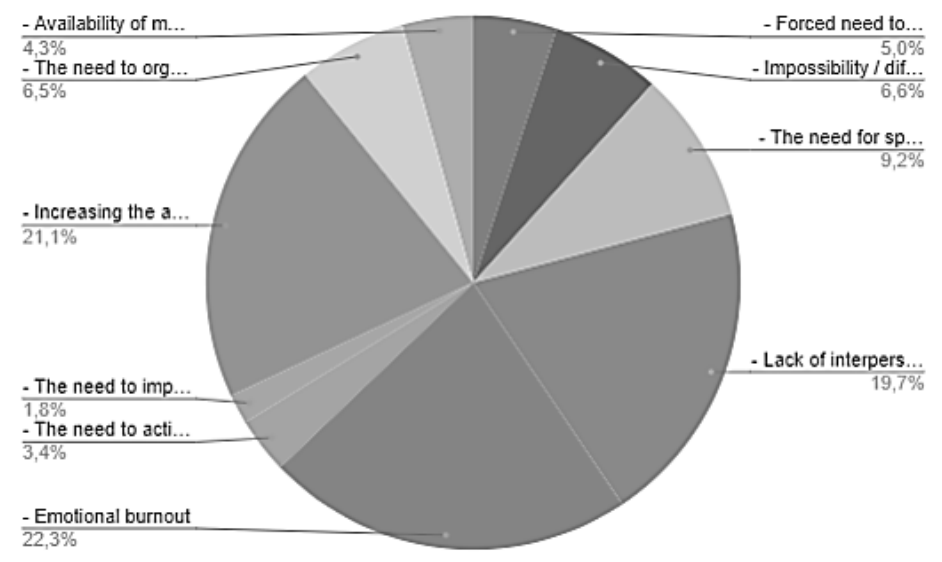

Figure 3. Distributed drawback features and elements of e-learning and hybrid learning: students of Oriental and European Languages programs (BGKU)

Top scoring features and elements of e-learning and hybrid learning, considered drawbacks, challenges or a hindrance by all groups of students of Oriental and European languages programs of all levels at Borys Grinchenko Kyiv University are: Emotional burnout $-70.80 \%$ of respondents; Increasing the amount of workload in preparation for training sessions and ensuring the learning process - 67.20\%; Lack of interpersonal communication with students and colleagues on a regular basis - $63 \%$.

The following prominent elements of educational process were identified and selected by respondents across all groups and Foreign Language Programs: Conducting lectures; Conducting practical classes; Development of training materials and materials for assessment; Execution of tasks (volumes, format, method of presentation); Organization of group work of students; Organization of independent work of students; Organization of creative work of students; Organization of research work; Communication with students (current); Communication with students (advisory); Informal communication outside the learning process / mentoring and moderation; Assessment (formative, summative, qualification).

Each element of the educational process was subjected to ranking by all groups of students according to the 5-point Likert Scale in terms of its efficiency for e-learning and hybrid learning quality assurance.

Students of Oriental and European languages programs of all levels have identified the following elements of the educational process and management as ranking highest (5 - most conductive for quality of e-learning and hybrid learning in individual experience): Conducting lectures $(54.3 \%$ of respondents); Organization of independent work of students $(45.6 \% \%)$; Development of training materials and materials for assessment (34.6\%); Conducting practical classes (34.1\%).

The following elements of the educational process and management were identified as ranking $2^{\text {nd }}$ highest by all groups of students (4 - mostly conductive for quality of e-learning and hybrid learning in individual experience): Summative assessment (37.1\%); Formative assessment (35.9\%); Qualification assessment (33.5\%); Execution of tasks (volumes, format, method of presentation) (29.1\%); Communication with students (current) $(30.26 \%)$.

The overall workload of educational activities for Foreign languages programs in the framework of e-learning and hybrid learning mode (Figure 4) was estimated by all groups of respondents as overwhelmingly increased (in terms of $10 \%$ increments) as compared to the years of study, proceeding 2020: Increased by a $100 \%-27.6 \%$ of respondents; Increased by $80 \%-17.5 \%$; Increased by $90 \%-15.3 \%$; Increased by $70 \%-11.3 \%$. 


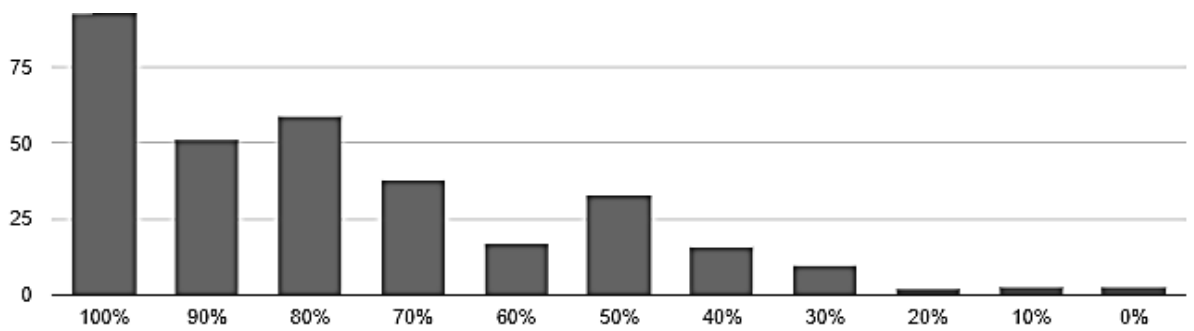

Figure 4. Increase of workload across educational activities for European and Oriental Languages programs (BGKU, Ukraine): students survey

Respondents of Oriental and European languages programs of all levels were asked to identify the e-learning and hybrid learning educational process elements that are conductive to quality of learning experiences outside of the COVID-19 framework and are preferable to be retained and implemented on a regular basis (Figure 5): Online classes through video conferencing systems; Online advisory sessions; Online implementation and defense of final / diploma projects; Use of electronic learning management system (LMS Moodle, Google Class etc.); Electronic tests and assessments online; Cloud technologies for collaboration; Cloud technologies for project presentation; Communication through electronic resources (mail, video, chat services, social networks); Use of e-textbooks and materials; Online interaction with the administration and methodological support; Time management; Possibility of study / research work at home or without binding to a place (ubiquitous learning); Ability to build an individual learning trajectory; Opportunity to utilize informal education resources.

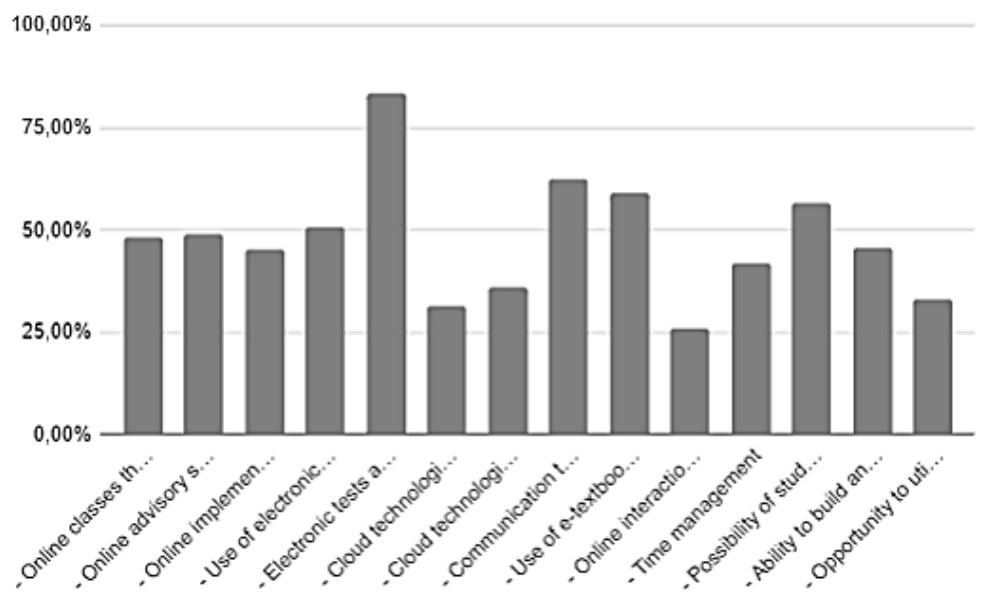

Figure 5. Elements that are conductive to quality of learning experiences outside of the COVID-19 framework: students survey (BGKU)

The following elements of hybrid and e-learning scored highest by students of European and Oriental languages programs at Borys Grinchenko Kyiv University scored highest as desirable to be retained and further implemented in the educational process outside of the COVID-19 limitation measures: Electronic tests and assessments online $-83.30 \%$ of respondents; Communication through electronic resources (mail, video, chat services, social networks) - 62.30\%; Use of e-textbooks and materials - 59.30\%; - Possibility of study / research work at home or without binding to a place (ubiquitous learning) $-56.80 \%$; Use of electronic learning management system (LMS Moodle, Google Class etc.) $-50.80 \%$.

Group 2 of survey questions - assessment of individual experiences and quality of e-learning and hybrid learning in the framework of COVID-19 lockdown as compared to traditional, face-to-face learning formats - yielded the following representative results across the board.

Respondents of all groups were asked to compare the individual experiences and estimations of quality and efficiency of traditional, face-to-face in-presence learning and hybrid or e-learning in the timeframe of 
the COVID-19 lockdown (respondents were instructed to disregard their individual assessment of blended learning or online learning prior to 2020).

The comprehensive comparison of individual experiences of traditional learning (TL) and e-learning (EL) was ranked according to the 5-point Likert Scale (5 - maximum quality and efficiency, 1 - minimum quality and efficiency). Students of Oriental and European languages programs of all levels at BGKU of Ukraine have ranked the comparative quality of traditional and e-learning in the following way: 4 - mostly qualitative and efficient (TL - 46\%, EL - 32.6\% of respondents); 5 - most qualitative and efficient (TL - 33.82\%, EL $22.8 \%$ of respondents); 3 - average in quality and efficiency (TL $-12.5 \%$, EL $-27.6 \%$ of respondents).

The average score of individual quality and efficiency comparison for traditional learning (TL) and e-learning (EL) by all groups of students in regional universities of Ukraine is 4 - mostly qualitative and efficient.

The students of all groups were prompted to contrast their individual assessment e-learning and hybrid learning against the prior to COVID-19 timeframe paradigm of experience of traditional in-presence learning. In-presence learning (TL) was estimated as a conventional $100 \%$ of potential quality of education process and learning outcomes for European and Oriental languages programs. Accordingly, the respondents were to scale their assessment of e-learning and hybrid learning quality from $0 \%$ (no correspondence to TL quality in individual experience) to $100 \%$ (full correspondence to TL quality in individual experience) in $10 \%$ increments (Figure 6):

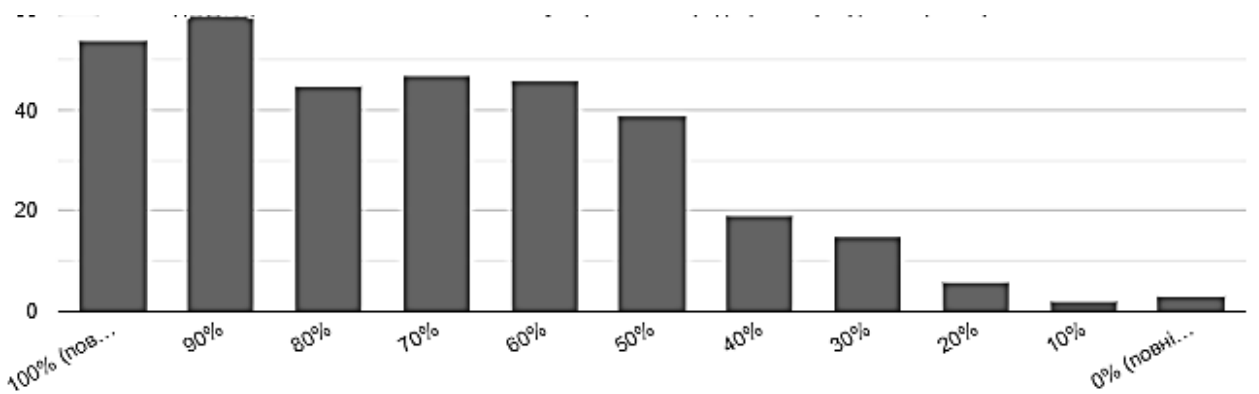

Figure 6. Distribution of contrastive assessment of e-learning and hybrid learning quality by students of European and Oriental languages programs (BGKU)

According to survey data of students of Oriental and European languages programs of all levels, e-learning and hybrid learning satisfaction in the timespan of COVID-19 score the highest quality approximation to traditional learning in such proportions: $90 \%$ of quality correspondence between EL and TL $-17.5 \%$; $100 \%$ of quality correspondence between EL and TL - 16.02\%; $70 \%$ of quality correspondence between EL and TL - $14 \%$.

Therefore, the average estimation of the quality correspondence between hybrid learning and traditional learning by students of Foreign Languages major programs at Borys Grinchenko Kyiv University is $85 \%$ majorly correspondent quality.

The accompanying social, educational and technological factors that contributed to this results in case of Borys Grinchenko Kyiv University are estimated as follows: 1) High level of digitalization (prior to quarantine measures), implementation of a functional e-learning environment (digital campus); 2) High level of blended learning implementation in the classrooms of European and Oriental languages surveyed (the implementation of a practice and applied skills oriented educational strategy at the university); 3) High level of digital literacy of students (individual and institutional - implemented through consistent digital literacy training at the university for all stakeholders); 4) High level of international mobility prior to quarantine measures that informed implementation of e-learning techniques and habitual usage of LMS.

Group 3 of survey questions - individual quality assessment of learning process design, programmed learning outcomes and projected competencies for university programs of European (French, Italian, Spanish, English) and Oriental (Mandarin Chinese, Japanese) languages in the framework of COVID-19 lockdown and quarantine measures (March 2020 - January 2021) - yielded the following representative results across the board.

Respondents of all groups were prompted to assess the degree of adaptation efficiency of each element of the educational process, heretofore identified as conductive to quality of e-learning and hybrid learning format in the framework of COVID-19. The scale of 5 (most efficiently adapted for e-learning and hybrid 
learning format) to 1 (least efficiently adapted for e-learning and hybrid learning format) was applied. Students of Oriental and European languages programs of all levels have identified the adaptation of the following elements of the educational process and management as ranking proportionately efficiently and mostly efficiently adapted for e-learning and hybrid learning format): Conducting lectures (77\% of respondents); Organization of independent work of students (75\% of respondents); Formative, Summative and Qualification Assessment (69.1\% of respondents); Conducting practical classes (67\% of respondents).

For the purposes of the survey inquiry, students of Oriental and European languages programs of all levels were prompted to evaluate the effectiveness of the formation of program competencies and learning outcomes in philology in the process of online and hybrid learning (from individual experience through the timespan of COVID-19 lockdown). The set of program competencies was estimated according to the official curriculum and syllabi, normative for the major programs in Oriental and European languages of any given year (Figure 7): Reflective practice; Self-development; Research activities; Time-management; Self-organization; Interpersonal skills; Teamwork; Stress management; Professional international mobility; Analysis of linguistic and communicative phenomena; Proficiency in oral foreign communication; Proficiency in written foreign communication; Public speaking skills; Intercultural competence; Translation (oral and written); Digital literacy; Literary competence; Pedagogical and methodological competence; Critical thinking in a professional context; Practical application of analytical conclusions based on linguistic and communicative data.

Each programmed competence was ranked according to the 5-point Likert Scale (5 - maximum quality and efficiency in achievement through online and hybrid learning, 1 - minimum quality and efficiency in achievement through online and hybrid learning) - Figure 7:

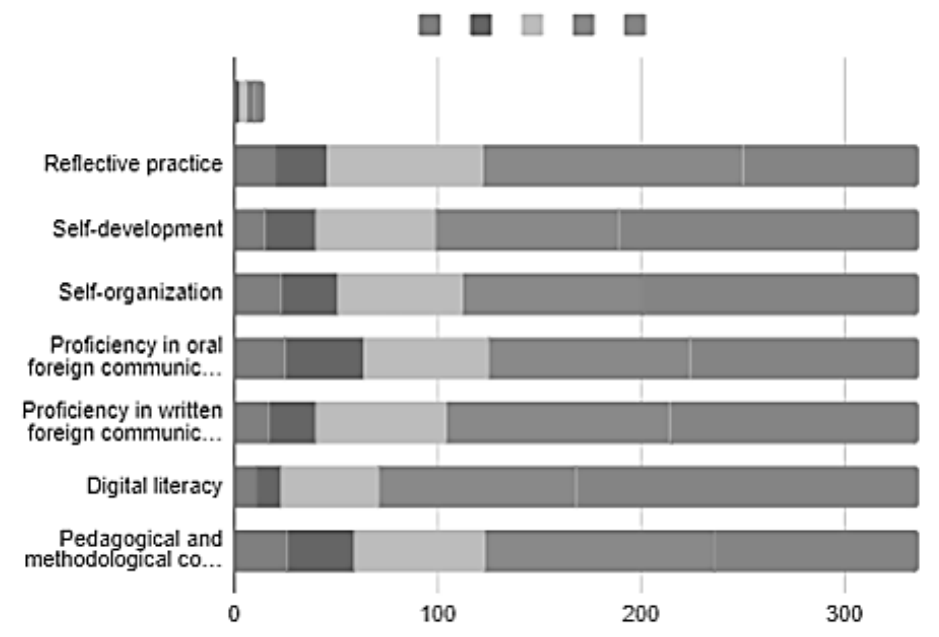

Figure 7. Effectiveness of the formation of program competencies and learning outcomes in philology in the process of online and hybrid learning (BGKU). Sample evaluation

Program competencies and learning outcomes in philology in the process of online and hybrid learning scoring highest ( 5 maximum quality and efficiency in achievement through online and hybrid learning) in individual estimation of students of Oriental and European Languages Programs through the timespan of spring and fall semesters of 2020 in COVID-19 lockdown) are as follows: Digital literacy- 50.1\% of respondents; Self-development - 44\% of respondents; Self-organization - 40.3\%; Proficiency in written foreign communication $-36.5 \%$; Proficiency in oral foreign communication $-33.5 \%$; Pedagogical and methodological competence $-30 \%$.

Respondents of all groups were prompted to identify the key challenges that impaired effective and qualitative adaptation of the learning process design into hybrid and digital distant format (Figure 8): 


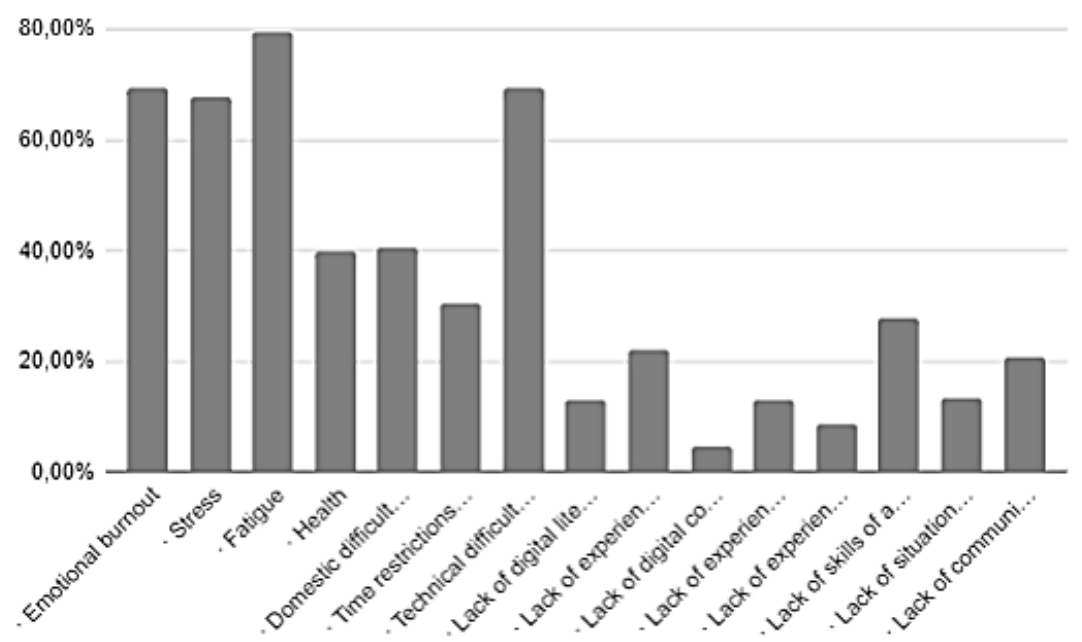

Figure 8. Ranking of challenges derived from the individual experiences of Oriental and European languages students in hybrid and e-learning (BGKU)

The following generic types of impediments (Figure 8) were derived from the individual experiences of Oriental and European languages programs students in the timeframe of COVID-19 in universities of Ukraine:

- Social and psychological: Emotional burnout; Stress; Fatigue; Health; Domestic difficulties / limitations; Time restrictions in connection with the introduction of quarantine restrictions.

- Technical challenges and digital literacy: Technical difficulties (lack of stable Internet connection, lack of necessary equipment, capacity of household computer equipment); Lack of digital literacy skills; Lack of experience in transforming the curriculum and training materials into an online format; Lack of digital communication experience; Lack of experience with electronic learning management systems (Moodle, GoogleClass, etc.); Lack of experience with auxiliary ICT tools for organizing the learning process (video conferencing, testing, surveys, online boards, etc.).

- Soft skills: Lack of skills of adaptation and self-organization; Lack of situational learning and training skills; Lack of communication and cooperation skills.

Students of Oriental and European languages programs of all levels at Borys Grinchenko Kyiv University of Ukraine have identified the following top scoring challenges and limitations (technical and socio-psychological) in efficient and qualitative transformation of educational elements into hybrid and e-learning format in their individual experience: Fatigue $-79.60 \%$ of respondents; Emotional burnout 69.60\%; Technical difficulties (lack of stable Internet connection, lack of necessary equipment, capacity of household computer equipment) $-69.30 \%$; Stress $-67.80 \%$.

It is notable that most of the challenges of the 'digital literacy' group feature as relatively insignificant (>13\% score) in individual experiences of students of all levels at a university of the capital city of Ukraine. Such distribution of technical challenges estimation testifies to the phenomenon of digital gap (DGR 2019; WEF 2020), pervasive in various areas of educational activities in the framework of Covid-19 lockdown. That placed students as an age group, as mostly representatives of the "digital native" generation - term by M. Prensky (2001) - people born or grown up through early formative years into the digital society (1995 year of birth onwards), at a significant advantage in the hybrid and digital educational process through the implementation of emergency quarantine measures of in 2020 and 2021.

\section{CONCLUSION}

The global pandemic and subsequent quarantine measures and restrictions have significant influence on the structure and procedure of higher education workflow, which informed significantly the scope of individual 
experiences, projected outcomes and estimated quality of higher education in the realm of Foreign languages acquisition in all regions of Ukraine.

The survey results on the individual experiences and quality assessment of e-learning and hybrid learning in the framework of COVID-19 lockdown yield comprehensive data on the parameters and challenges of e-learning and hybrid learning transformation of Oriental and European languages programs, common for students of higher educational institutions of the capital city of Ukraine - Kyiv.

Overall individual experiences and quality estimation of e-learning and hybrid learning in the framework of COVID-19 lockdown and quarantine measures (March 2020 - January 2021) for regional university programs of European (English, French, Spanish, Italian) and Oriental (Mandarin Chinese, Japanese) languages are assessed as mostly agreeable to most agreeable by all groups of students across educational levels.

The qualitative assessment of the e-learning and hybrid learning was conducted through the retrospective evaluation of respondents' individual experience that helped identify the comparative coordinates of positive and negative dimensions of the latter. The invariant positive quality indicators for e-learning and hybrid learning across all groups of students surveyed are the opportunity for multitasking, digital skills improvement and lack of commute expenditure. The invariant negative quality indicators for e-learning and hybrid learning across all groups of students surveyed are the lack of interpersonal communication, technical impediments and psychological states (fatigue, burnout, stress).

The contrastive exposure of individual experiences and quality of e-learning and hybrid learning in the framework of COVID-19 lockdown against the backdrop of traditional, in-presence learning formats identify e-learning and hybrid learning as mostly to average comparative in quality for foreign languages stakeholders at Borys Grinchenko Kyiv University of Ukraine.

Assessment of learning process design, programmed learning outcomes and projected competencies for university programs of Oriental (Mandarin Chinese, Japanese) and European (French, Italian, Spanish, English) languages in the framework of COVID-19 lockdown allowed to identify the types of challenges that impaired effective and qualitative adaptation of learning process design into hybrid and digital distant format as predominantly socio-psychological for students of all groups surveyed.

The presented study is limited in scope to the indicative survey results, exemplifying the outlined quality assurance dimensions of e-learning and hybrid learning implementation for Oriental and European languages programs in the capital city university of Ukraine, induced by COVID-19 measures. The perspectives of the inquiry include fine-tuned estimation of the in-depth subjective quality assessment and subsequent efficiency assessment of hybrid and e-learning in different regions of Ukraine; contrastive case studies of Oriental and European languages programs emergency digital distance format adaptations in the COVID-19 timespan in universities of regional and national status; contrastive case studies and best practices of Oriental and European languages programs transformation to hybrid and e-learning format in countries of Europe and Asia upon alleviation of COVID-19 restrictive measures.

\section{ACKNOWLEDGEMENT}

Empirical findings and survey procedures have been conducted under the auspices of Integrated Research framework of Romance Languages and Typology Chair of Borys Grinchenko Kyiv University European Languages And Literatures Development In Cross-Communication Context (0116U006607) and Integrated Research framework of Oriental Languages and Translation Chair of Borys Grinchenko Kyiv University Oriental Studies Development in the framework of Higher Education Internationalization (0116U007073).

\section{REFERENCES}

Almalki, S. 2016. Integrating Quantitative and Qualitative Data in Mixed Methods Research - Challenges and Benefits. Journal of Education and Learning, 5(3), pp. 288-296.

Bekele, T. A., 2010. Motivation and satisfaction in internet-supported learning environments: A review. Educational Technology \& Society, 13(2), pp. 116-127. 
Bolliger, D. U. \& Wasilik O., 2009. Factors influencing faculty satisfaction with online teaching and learning in higher education. Distance Education, 30(1), pp.103-116.

Boyarsky K., 2020. What is Hybrid Learning. eThink. Retrieved from: https://www.owllabs.com/blog/hybrid-learning

Costareie, S., 2011. Assuaring quality based on the assessment of learning outcomes. 5th International Technology, Education and Development. Conference (INTED) Mar. 07-09, 2011, pp. 3235-3236.

Crowe, A. R., 2007. Learning to teach with mobile technology: A teacher educator's journey. In M. van 't Hooft \& K. Swan (Eds.), Ubiquitous computing in education. Mahwah, New Jersey: Lawrence Erlbaum Associates, pp. $127-144$.

Dillman, D. A., Smyth, J. D., Christian, Leah Melani, 2014. Internet, Phone, Mail and Mixed-Mode Surveys: The Tailored Design Method, 4th edition. John Wiley: Hoboken, NJ.

Dos Reis A., 2015. To Be a (Blended) Teacher in the 21st Century - Some Reflections. International Journal of Research in E-learning, 1(1), pp. 11-24.

DQ Global Standards Report, 2019. World's first global standard for digital literacy, skills and readiness launched by the Coalition for Digital Intelligence. Retrieved from: https://www.dqinstitute.org/ (accessed July 2020).

Duff C., 2020. Everything you need to know about education, technology and distance learning. eThink, Retrieved from: https://www.owllabs.com/blog/hybrid-learning

European Commission, 2020. European E-Competence Framework Guideline. Retrieved from: https://www.ecompetences.eu/ (accessed July 2020).

Handbook of Disease Burdens and Quality of Life Measures, 2010. Springer Science+Business Media, pp 4288-4288.

Law of Ukraine, 2019. On Higher Education. Retrieved from: https://zakon.rada.gov.ua/laws/show/1556-18\#Text (accessed July 2020).

Makhachashvili, R., Semenist, I., 2021. Complex Framework of Digital Learning Quality Assessment in Covid-19 Context: Survey Study for European and Oriental Languages Programs. Proceedings of the 6th International Conference on Complexity, Future Information Systems and Risk. Lisbon, Portugal, pp. 107-116.

Makhachashvili, R., Semenist, I., \& Bakhtina, A., 2020. Digital Skills Development And Ict Tools For Final Qualification Assessment: Survey Study For Students And Staff Of European And Oriental Philology Programs, Electronic Scientific Professional Journal "Open Educational E-Environment Of Modern University, (9), 2020, pp. 54-68. https://doi.org/10.28925/2414-0325.2020.9.5

Makhachashvili, R., Semenist, I., \& Bakhtina, A., 2020. ICT Tools and Practices for Final Qualification Assessment in the Framework of COVID-19 Lockdown, Innovative Educational Technologies, Tools and Methods for E-learning Monograph. University of Silesia in Katowice, Poland, Katowice, pp. 183-194.

Markova, T., Glazkova, I., \& Zaborova, E. 2017. Quality Issues of Online Distance Learning. Social and Behavioral Sciences, (237), pp. $685-691$.

Ni, A. Y., 2013. Comparing the effectiveness of classroom and online learning: Teaching research methods. Journal of Public Affairs Education, 2013, 19(2), 199-215.

Prensky, M. 2001. Digital Natives, Digital Immigrants. On the Horizon, Vol. 9 No. 5.

Salyers, V., Carter, L., Carter, A., Myers, S., \& Barrett, P., 2014. The search for meaningful e-learning at Canadian universities: A multi-institutional research study. The International Review of Research in Open and Distributed Learning, 15(6), 2014, 313-347.

Smyrnova-Trybulska, E., Kommers P. et al (Eds). 2019. Universities in the Networked Society. Springer.

Thiessen J \& Ambrock V. 2011. Value Added - The Editor in Design and Development of Online Courses. The Theory and Practice of Online Learning, AU Press, Athabasca University. Retrieved from: https://read.aupress.ca/read/thetheory-and-practice-of-online-learning/section/7b34c0dd-89ad-4280-9c95-137c1e2aa471\#ch11

Trentin G. 2010. Networked Collaborative Learning: Social Interaction and Active Learning. Springer.

Tu, Pierre N. V. 1994. Dynamical systems : an introduction with applications in economics and biology. Berlin New York: Springer.

Van 't Hooft, M., Swan, K., Lin, Y-M., \& Cook, D. 2007. What is ubiquitous computing? Ubiquitous Computing in Education, pp. 3-17.

Voorn, R. J., \& Kommers, P. A. 2013. Social media and higher education: introversion and collaborative learning from the student's perspective. International Journal of Social Media and Interactive Learning Environments, 1(1), pp. 59-73.

World Economic Forum, 2020. The Future of Jobs Report. Retrieved from: http://www3.weforum.org/docs/WEF_Future_of_Jobs_2020.pdf (accessed November 2020). 